\title{
Effects of low-fat dairy intake on blood pressure, endothelial function, and lipoprotein lipids in subjects with prehypertension or stage I hypertension
}

\author{
This article was published in the following Dove Press journal: \\ Vascular Health and Risk Management \\ 19 July 2013 \\ Number of times this article has been viewed
}

\author{
Kevin C Maki ${ }^{1}$ \\ Tia M Rains' \\ Arianne L Schild' \\ Mary R Dicklin' \\ Keigan M Park ${ }^{2}$ \\ Andrea L Lawless' \\ Kathleen M Kelley' \\ 'Biofortis Clinical Research, Addison, \\ IL, USA; ${ }^{2}$ Dairy Research Institute/ \\ National Dairy Council, Rosemont, \\ IL, USA
}

\begin{abstract}
Objective: This randomized crossover trial assessed the effects of 5 weeks of consuming low-fat dairy (one serving/day each of $1 \%$ fluid milk, low-fat cheese, and low-fat yogurt) versus nondairy products (one serving/day each of apple juice, pretzels, and cereal bar) on systolic and diastolic blood pressures (SBP and DBP), vascular function (reactive hyperemia index [RHI] and augmentation index), and plasma lipids.

Methods: Patients were 62 men and women (mean age 54.5 years, body mass index $29.2 \mathrm{~kg} / \mathrm{m}^{2}$ ) with prehypertension or stage 1 hypertension (mean resting SBP/DBP $129.8 \mathrm{mmHg} / 80.8 \mathrm{mmHg}$ ) while not receiving antihypertensive medications. A standard breakfast meal challenge including two servings of study products was administered at the end of each treatment period.

Results: Dairy and nondairy treatments did not produce significantly different mean SBP or DBP in the resting postprandial state or from premeal to 3.5 hours postmeal (SBP, $126.3 \mathrm{mmHg}$ versus $124.9 \mathrm{mmHg}$; DBP, $76.5 \mathrm{mmHg}$ versus $75.7 \mathrm{mmHg}$ ), premeal (2.35 versus 2.20) or 2 hours postmeal (2.33 versus 2.30) RHI, and premeal (22.5 versus 23.8 ) or 2 hours postmeal (12.4 versus 13.2) augmentation index. Among subjects with endothelial dysfunction $(\mathrm{RHI} \leq 1.67$; $\mathrm{n}=14$ ) during the control treatment, premeal RHI was significantly higher in the dairy versus nondairy condition (2.32 versus $1.50, P=0.002$ ). Fasting lipoprotein lipid values were not significantly different between treatments overall, or in subgroup analyses.

Conclusion: No significant effects of consuming low-fat dairy products, compared with low-fat nondairy products, were observed for blood pressures, measures of vascular function, or lipid variables in the overall sample, but results from subgroup analyses were consistent with the hypothesis that dairy foods might improve RHI in those with endothelial dysfunction.
\end{abstract}

Keywords: blood pressure, dairy, endothelial function, hypertension, lipids

\section{Introduction}

Hypertension, defined as systolic blood pressure $(\mathrm{SBP}) \geq 140 \mathrm{mmHg}$ and/or diastolic blood pressure (DBP) $\geq 90 \mathrm{mmHg}$, is a common condition worldwide. ${ }^{1}$ In the United States alone it affects $\sim 31 \%$ of adults aged at least 20 years of age; $64 \%$ and $69 \%$ of men and women aged 65-74 years of age, respectively; and $72 \%$ and $81 \%$ of men and women aged 75 years and above, respectively. ${ }^{2}$ Hypertension is a major risk factor for the development of stroke, coronary heart disease (CHD), heart failure, and endstage renal disease. ${ }^{3}$ Prehypertension, defined as SBP 120-139 $\mathrm{mmHg}$ and/or DBP $80-89 \mathrm{mmHg}$, has a prevalence of $30 \%$ in the US population. ${ }^{4,5}$ The designation of prehypertension was created to identify individuals at risk who might reduce their risk
Correspondence: Kevin C Maki Biofortis Clinical Research, 2II E Lake Street, Addison, IL, USA 60101

$\mathrm{Tel}+\mathrm{I} 6305163800$

$\mathrm{Fax}+\mathrm{I} 6305164033$

Email kevin.maki@mxns.com 
for progression to hypertension by adopting healthy diet and lifestyle practices. ${ }^{4}$

Diet is one of the strongest environmental factors influencing blood pressure. ${ }^{6}$ The Dietary Approaches to Stop Hypertension (DASH) trial demonstrated that a dietary pattern that reduced total and saturated fat intakes, included low-fat dairy products, and was rich in fruits and vegetables significantly lowered blood pressure in normotensive and hypertensive individuals. ${ }^{7}$ Furthermore, the low-fat dairy-containing diet resulted in a more pronounced blood pressure-lowering effect than a diet rich in fruits and vegetables without dairy. ${ }^{7}$ Results from other cross-sectional and prospective observational studies and randomized clinical trials have also suggested an inverse association between consumption of dairy products, particularly low-fat products, and the risk of developing hypertension. ${ }^{8-20} \mathrm{~A}$ recent metaanalysis reported a relative risk of 0.87 (95\% confidence interval, 0.81-0.94) for the development of elevated blood pressure in adults consuming higher versus lower quantities of dairy. ${ }^{19}$ Evidence from intervention studies examining the effects of dairy products on blood pressure is limited, but results from a recent trial of 35 healthy overweight and obese men and women indicated that daily consumption of low-fat dairy products versus carbohydrate-rich products for 8 weeks significantly reduced SBP by $2.9 \mathrm{mmHg}(P=0.027) .{ }^{18}$

The mechanisms responsible for the association between consumption of dairy products and lower risk for hypertension have not been fully defined. Endothelial dysfunction is regarded as an early pivotal event in the development of hypertension, and has been linked to increased risk for clinical cardiovascular events such as myocardial infarction and cardiac death. ${ }^{21}$ Reactive hyperemia index (RHI) values measured by peripheral arterial tomography have been shown to be predictive of cardiovascular outcomes. ${ }^{22}$ A single highfat meal produces an acute endothelial insult, as evidenced by a decline in brachial artery flow-mediated dilation after a period of occlusion-induced ischemia. ${ }^{23-31}$ Studies have shown that ingestion of selected foods and nutrients can reduce or prevent the acute endothelial dysfunction induced by a high-fat meal. ${ }^{24,25,32-36}$ Chaves et $\mathrm{al}^{35}$ demonstrated that acute and chronic consumption by healthy normal subjects of grape products equivalent to 1.25 cups of fresh grapes did not affect heart rate, hemodynamics, or lipids, but completely prevented high-fat meal-induced endothelial dysfunction. Interventions such as aerobic exercise training, weight loss, smoking cessation, and drug therapies to treat hypertension, dyslipidemia, and hyperglycemia have also been shown to improve endothelial function. ${ }^{37-41}$
This study was designed to assess the effects of consuming low-fat dairy versus nondairy products on fasting and postprandial blood pressures, endothelial function, and fasting lipoprotein lipids in men and women with prehypertension or stage 1 hypertension (SBP 140-159 mmHg and/or DBP 90-99 $\mathrm{mmHg}$ ), who were not receiving antihypertensive medication.

\section{Methods}

Study design

This randomized, controlled, two-period crossover study was conducted at Biofortis Clinical Research (Addison, IL, USA) according to Good Clinical Practice Guidelines, the Declaration of Helsinki (2000), and the United States 21 Code of Federal Regulations. It included seven clinic visits: two during screening, two at the conclusion of both 5-week treatment periods, and one after a two-week washout period between treatment periods. In addition, subjects were contacted by telephone 2 weeks into each 5 -week treatment period in order to reinforce dietary instructions. The study protocol was approved by an Institutional Review Board (Quorum Review IRB, Seattle, WA, USA), and a signed informed consent form and authorization for disclosure of protected health information were obtained from all subjects before protocol-specific procedures were carried out. Subjects were informed of their right to withdraw from the study at any time.

After assessment of entry criteria, eligible subjects were randomly assigned to one of two treatment sequences: consumption of dairy products during the first 5-week treatment period and nondairy products during the second 5-week treatment period, or vice versa. The treatment periods were separated by a washout period of at least 2 weeks. During the dairy product treatment period, subjects incorporated into their diets 1 serving/day each of $1 \%$ fluid milk, low-fat cheese, and low-fat yogurt, and during the nondairy product treatment period, subjects incorporated into their diets 1 serving/day each of apple juice, pretzels, and a cereal bar (Table 1). All subjects were instructed to consume $\leq 1$ serving/day of other dairy foods during each treatment period. A registered dietitian counseled the subjects on how to incorporate the dairy or nondairy study products into their diets while maintaining caloric balance and avoiding consumption of more than 1 serving/day of nonstudy dairy products throughout the trial. Dairy and nondairy products were provided; subjects picked up the study products approximately every 2 weeks during the study. They maintained a daily study product log and returned 
Table I Nutritional composition of study products (per serving) ${ }^{\mathrm{a}}$

\begin{tabular}{|c|c|c|c|c|c|c|}
\hline \multirow[t]{2}{*}{ Nutrient } & \multicolumn{3}{|c|}{ Dairy products } & \multicolumn{3}{|c|}{ Nondairy products } \\
\hline & $\begin{array}{l}\text { Low-fat } \\
(1 \%) \text { milk } \\
(8 \mathrm{oz})^{\mathrm{b}}\end{array}$ & $\begin{array}{l}\text { Low-fat Yoplait } \\
\text { strawberry } \\
\text { yogurt ( } 6 \mathrm{oz})\end{array}$ & $\begin{array}{l}\text { Part-skim } \\
\text { mozzarella string } \\
\text { cheese ( }(\mathrm{loz})\end{array}$ & $\begin{array}{l}\text { Juicy Juice } \\
\text { apple juice } \\
\text { (6.75 fl oz) }\end{array}$ & $\begin{array}{l}\text { Special K } \\
\text { chocolate chip } \\
\text { cereal bar ( } 23 \mathrm{~g})\end{array}$ & $\begin{array}{l}\text { Snyder's } \\
\text { pretzels } \\
(0.9 \mathrm{oz})\end{array}$ \\
\hline Energy (kcal) & 110 & 100 & 80 & 100 & 90 & 110 \\
\hline Carbohydrate (g) & 13 & 21 & 1 & 24 & 18 & 22 \\
\hline Protein $(\mathrm{g})$ & 8 & 5 & 8 & 0 & 1 & 2 \\
\hline Fat $(g)$ & 2.5 & 0 & 6 & 0 & 1.5 & 0 \\
\hline Calcium (mg) & 300 & 200 & 200 & 0 & 0 & 0 \\
\hline Potassium (mg) & $500^{c}$ & 260 & $27^{c}$ & 190 & $68^{c}$ & $39^{c}$ \\
\hline Sodium (mg) & 130 & 100 & 200 & 15 & 100 & 280 \\
\hline Magnesium (mg) & $27^{c}$ & $19^{c}$ & $7^{c}$ & $10^{c}$ & $10^{c}$ & $8^{c}$ \\
\hline Dietary fiber $(\mathrm{g})$ & 0 & 0 & 0 & 0 & 3 & $I^{c}$ \\
\hline
\end{tabular}

Notes: axact study products varied slightly depending on availability. All study products were commercially available food products providing roughly the same nutritional content as described in the examples above; lactose-free $1 \%$ milk was provided to subjects when appropriate; 'content was not available on the food label or in the FoodPro database. Value was estimated from the United States Department of Agriculture database that related to the specific food product.

unconsumed servings of the study products to the clinic for determination of study product compliance.

\section{Subjects}

Participants included normally active, healthy men and postmenopausal women 20-69 years of age, inclusive, each with a body mass index of $18.5-39.9 \mathrm{~kg} / \mathrm{m}^{2}$ and with resting blood pressure at screening meeting the criteria for prehypertension (SBP 120-139 mmHg and/or DBP 80-89 mmHg) or stage 1 hypertension (SBP 140-159 mmHg and/or DBP 90-99 $\mathrm{mmHg}$ ). Volunteers were ineligible for participation if they had SBP $\geq 160 \mathrm{mmHg}$ or DBP $\geq 100 \mathrm{mmHg}$. Subjects were also required to have a history of consumption, on average, of $\leq 2$ servings/day of dairy foods as part of their normal diets, and to be willing to consume $\leq 1$ serving/day of dairy foods, other than the study products provided, during each treatment phase. Additional requirements were to maintain stable body weight, habitual alcohol intake and smoking habits, physical activity patterns, use of vitamin and/or mineral supplements, and diet (other than the study products) throughout the trial. Subjects were also required to avoid vigorous physical activity and alcohol consumption 24 hours prior to each clinic visit, and to abstain from tobacco products at least 1 hour prior to and during each clinic visit.

Individuals were excluded if they had known CHD or a CHD risk equivalent including diabetes mellitus or fasting glucose $\geq 126 \mathrm{mg} / \mathrm{dL}$; clinical signs of atherosclerosis including peripheral arterial disease, abdominal aortic aneurysm, carotid artery disease (symptomatic [eg, transient ischemic attack or stroke of carotid origin] or $>50 \%$ stenosis on angiography or ultrasound) or other forms of clinical atherosclerotic disease (eg, renal artery disease); or the presence of multiple risk factors that confer greater than $20 \%$ probability for developing coronary artery disease within 10 years (Framingham Risk Score). ${ }^{42}$ Subjects with a history of clinically important endocrine, cardiovascular, pulmonary, biliary or gastrointestinal disorders that, in the opinion of the investigator, might interfere with the interpretation of the study results were also excluded, as were those with a history of cancer in the prior 2 years (except for nonmelanoma skin cancer), history of any major trauma or major surgical event within 2 months, an active infection or taking antibiotic therapy, extreme dietary habits or a history of an eating disorder, recent history or strong potential for alcohol or substance abuse, a latex allergy or allergy/sensitivity to any of the study products or ingredients in the study products or breakfast challenge meal, or digital deformities that would prevent endothelial function measurements. Subjects who had abnormal laboratory test results of clinical importance at screening, including but not limited to total cholesterol (total-C) $>300 \mathrm{mg} /$ $\mathrm{dL}$, triglyceride ( $\mathrm{TG}$ ) concentration $\geq 400 \mathrm{mg} / \mathrm{dL}$, alanine aminotransferase or aspartate aminotransferase $\geq 1.5$ times the upper limit of normal, and/or creatinine $\geq 1.5 \mathrm{mg} / \mathrm{dL}$ were also excluded.

The use of medications or dietary supplements with the potential to influence blood pressure or endothelial function; unstable use (initiation or change in dose) of lipid-altering supplements, ingredients, and/or drugs, including statins, bile acid sequestrants, cholesterol absorption inhibitors, fibrates, or prescription formulations of niacin; use of medications known to alter body weight (including over-the-counter medications) or weight loss supplements/foods; and use of meal replacement products or programs for weight loss purposes were not allowed within 4 weeks prior to screening. 


\section{Assessments}

To ensure that subjects were well hydrated at each clinic visit, they were dispensed a $500 \mathrm{~mL}$ bottle of water and instructed to consume the full volume of water, but no other foods or beverages, the morning of their next clinic visit. Seated, resting SBP, DBP, and heart rate were measured at each clinic visit; five measurements were taken, each separated by $\sim 3$ minutes, and the final four measurements were averaged (the first was discarded). Additionally, at weeks 5 and 12 , subjects underwent a breakfast meal challenge by consuming two servings of their assigned study products as part of a standard breakfast meal providing approximately $600 \mathrm{kcal}$ (50\% carbohydrate, $15 \%$ protein, and 35\% fat). Subjects were allowed 20 minutes to consume the breakfast meal. Seated, resting blood pressure and heart rate were assessed premeal $(\mathrm{t}=-1.0$ hour $)$ and at $\mathrm{t}=0.5,1.5,2.5$, and 3.5 hours, where $t=0$ hour was the start of the test meal consumption. As described above, five measurements were taken at each time point and the final four values were averaged. Additionally, endothelial function was assessed premeal $(\mathrm{t}=-0.5$ hour $)$ and at $\mathrm{t}=2 \pm 0.25$ hour using the EndoPAT System (Itamar Medical, Franklin, MA, USA), which measures peripheral arterial tone (PAT) in the index fingers of both hands simultaneously. ${ }^{43}$ The RHI is a ratio of the post-to-preocclusion PAT amplitude of the tested arm, divided by the post-to-preocclusion ratio of the control arm. An augmentation index (AI), a measure of wave reflection and arterial stiffness calculated as a ratio from the blood pressure waveform, was also determined.

Fasting (9-15 hours) blood samples were collected for analysis of the lipid profile [total-C, high-density lipoprotein (HDL)-C, non-HDL-C (total-C minus HDL-C), low-density lipoprotein (LDL)-C, total-C/HDL-C, and TG] at every clinic visit. Laboratory analyses were performed by Elmhurst Memorial Hospital Laboratory (Elmhurst, IL, USA). Samples were analyzed according to the Standardization Program of the Centers for Disease Control and Prevention and the National Heart, Lung and Blood Institute. LDL-C concentration in $\mathrm{mg} / \mathrm{dL}$ was calculated according to the Friedewald equation $^{44}$ as follows: LDL-C $=$ total-C - HDL-C $-\mathrm{TG} / 5$. This equation is not valid when the TG concentration is $>400 \mathrm{mg} / \mathrm{dL}$; therefore, LDL-C was not calculated under those circumstances. Subjects also collected 24-hour urine samples the day prior to the final clinic visit of each treatment period (weeks 5 and 12). Urine samples were analyzed for creatinine, electrolytes, and minerals (sodium, potassium, magnesium, chloride, and calcium). Adverse events and body weight were also assessed at each clinic visit.
Subjects completed 3-day diet records recording all foods and beverages consumed in the 3 days prior to the baseline visit and at the end of each treatment period (weeks 5 and 12). The diet record from the baseline visit was given back to the subjects with instructions to replicate the same food and beverage choices, other than the study products consumed, where appropriate, on the day prior to the clinic visits at weeks 4, 5, 11, and 12. Analysis of diet records was performed using Food Processor ${ }^{\circledR}$ SQL Nutrition Analysis and Fitness Software (version 10.4.0, ESHA Research, Salem, OR, USA).

\section{Statistical analyses}

Statistical programming and analyses were performed using SAS for Windows, version 9.2 (SAS Institute, Cary, NC, USA). All tests of significance, unless otherwise stated, were performed at alpha $=0.05$, two-sided. The targeted evaluable sample size of 57 subjects was expected to provide $80 \%$ power to detect a difference of $2.6 \mathrm{mmHg}$ in SBP (total area under the curve [AUC] divided by 3.5 hours), assuming a pooled standard deviation of $6.8 \mathrm{mmHg}$ for the SBP response (standardized effect size of 0.38 ). ${ }^{18}$

Demographic, baseline, and safety analyses were performed on data collected from all subjects who were randomized and consumed at least one dose of study product. Efficacy evaluable analyses were performed on the sample of subjects who were randomized and provided at least one postrandomization outcome data point during each treatment phase. In addition, efficacy analyses were performed on data from the per protocol population, identified as a subset of the efficacy evaluable population, in which subjects were excluded for reasons such as violations of inclusion or exclusion criteria or noncompliance with the study protocol. The results from the efficacy evaluable sample are described herein; per protocol results did not differ materially and are therefore not presented.

Baseline comparability of treatment sequence groups for demographic, lipid parameters, and blood pressure variables were assessed by analysis of variance (ANOVA) or chi-square tests. The primary outcome variable was the total AUC for SBP for the two test conditions obtained premeal and at postmeal time points divided by 3.5 to obtain an average value throughout the test period. Secondary outcome variables included a comparable calculation for DBP, RHI, and AI for the two test conditions premeal and at 2 hours after the start of meal consumption, SBP and DBP at each of the time points, as well as percent changes from baseline (average of weeks -1 and 0 ) to end of each 
treatment (average of weeks 4 and 5 and average of weeks 11 and 12) in the fasting lipid profile variables. Differences between conditions in responses were assessed using SAS Proc Mixed repeated measures ANOVA. Initial repeated measures ANOVA models contained terms for treatment, sequence, and treatment by sequence, with subject as a random effect. Models were reduced in a stepwise manner until only significant $(P<0.05)$ terms or treatment remained in the model. Assumptions of normality of residuals were investigated for each response measurement. In cases where the normality assumption was rejected at the $1 \%$ level with the Shapiro-Wilks test, ${ }^{45}$ an analysis using ranks was performed. Examination of responses by sequence suggested that no material differences were present that would bring into question the appropriateness of pooling data from the two sequence groups. Differences in the incidence of adverse events between treatments were assessed with McNemar's test. ${ }^{46}$

Subgroup analyses were conducted to examine responses in blood pressure and endothelial function in subjects with prehypertension versus stage 1 hypertension, age (split at the median, $\leq 54$ years and $>54$ years of age), body mass index (split at the median $\leq 28.5 \mathrm{~kg} / \mathrm{m}^{2}$ and $>28.5 \mathrm{~kg} / \mathrm{m}^{2}$ ), non-Hispanic white versus those with other race/ethnicity, and baseline (premeal assessment during the nondairy phase) $\mathrm{RHI} \leq 1.67$ or $>1.67$. The cut-point of $\leq 1.67$ is recommended by the manufacturer of the EndoPAT device, to define endothelial dysfunction. ${ }^{47,48}$

\section{Results}

Of the 121 individuals screened for participation in the study, 73 were randomized and included in the safety population, and 62 subjects completed the study (29 in the dairy/ nondairy sequence and 33 in the nondairy/dairy sequence) and were included in the efficacy evaluable population. Of the eleven subjects who discontinued from the study, six withdrew consent, two were lost to follow-up, one discontinued due to starting blood pressure medication use during the trial, one was removed from the trial due to noncompliance, and one subject discontinued due to an adverse event classified as moderate dyspepsia, which was judged by the study physician to probably be related to consumption of the study products.

Demographic and baseline characteristics of all randomized subjects are listed in Table 2 . The majority of subjects were non-Hispanic white $(68 \%)$ and male $(55 \%)$ with average age of 54.7 years and body mass index of $29.2 \mathrm{~kg} / \mathrm{m}^{2}$. Mean baseline SBP and DBP were in the prehypertension
Table 2 Baseline demographic, anthropometric, and hemodynamic characteristics of subjects

\begin{tabular}{ll}
\hline Characteristic & Value, $\mathbf{N}=\mathbf{6 2}$ \\
\hline & $\mathbf{n}(\%)$ \\
Male & $34(54.8)$ \\
Female & $28(45.2)$ \\
Race/ethnicity & \\
Non-Hispanic white & $42(67.7)$ \\
Black/African American & $16(25.8)$ \\
Asian or Pacific Islander & $4(6.5)$ \\
Prehypertension & $52(83.9)$ \\
Stage I hypertension & $10(16.1)$ \\
& Mean $\pm \mathbf{S E M}$ \\
Age (years) & $54.7 \pm 1.2$ \\
Body weight (kg) & $86.2 \pm 2.1$ \\
Body mass index (kg/m $\left.{ }^{2}\right)$ & $29.2 \pm 0.6$ \\
Hemodynamic variables & \\
Systolic blood pressure $(\mathrm{mmHg})$ & $129.8 \pm 0.9$ \\
Diastolic blood pressure $(\mathrm{mmHg})$ & $80.8 \pm 0.9$ \\
Heart rate (beats $/$ minute) & $67.8 \pm 1.0$ \\
\hline
\end{tabular}

Abbreviation: SEM, standard error of the mean.

range, $130 \mathrm{mmHg}$ and $81 \mathrm{mmHg}$, respectively, reflecting that the majority of participants had prehypertension (84\%), and fewer had stage 1 hypertension (16\%). Overall median (interquartile limits) compliance with consumption of study products was $100 \%(99.0 \%, 103 \%)$ during the dairy products treatment and $100 \%(98.1 \%, 102 \%)$ during the nondairy products treatment $(P=0.149)$; because subjects were provided with more servings of study food than were required, some consumed slightly more than the recommended three servings on some days. Mean \pm SEM body weight was not different during dairy $(86.2 \mathrm{~kg} \pm 2.0 \mathrm{~kg})$ and nondairy treatments $(86.2 \mathrm{~kg} \pm 2.1 \mathrm{~kg})$.

Mean SBP and DBP values from before the meal challenge ( -1.0 hour) through time points up to 3.5 hours after consumption of the test meal (calculated as total AUC divided by 3.5 hours) are shown in Figure $1 \mathrm{~A}$ and B, respectively. There were no significant differences between dairy and nondairy treatments in mean SBP or DBP from premeal to 3.5 hours postmeal (SBP, $126.3 \mathrm{mmHg}$ versus $124.9 \mathrm{mmHg}$; DBP, $76.5 \mathrm{mmHg}$ versus $75.7 \mathrm{mmHg}$ ).

RHI and AI for dairy and nondairy treatments before and after a meal challenge in all subjects, and in the subgroup of 14 subjects with premeal endothelial dysfunction during the control condition (defined as RHI $\leq 1.67$ ), are shown in Table 3. There were no significant differences between dairy and nondairy treatments in premeal or 2 hours postmeal values in the overall sample. Among subjects with endothelial dysfunction who had a mean age of 56.7 years and resting $\mathrm{SBP} / \mathrm{DBP}$ of $128.1 \mathrm{mmHg} / 79.5 \mathrm{mmHg}$, the mean $\pm \mathrm{SEM}$ 

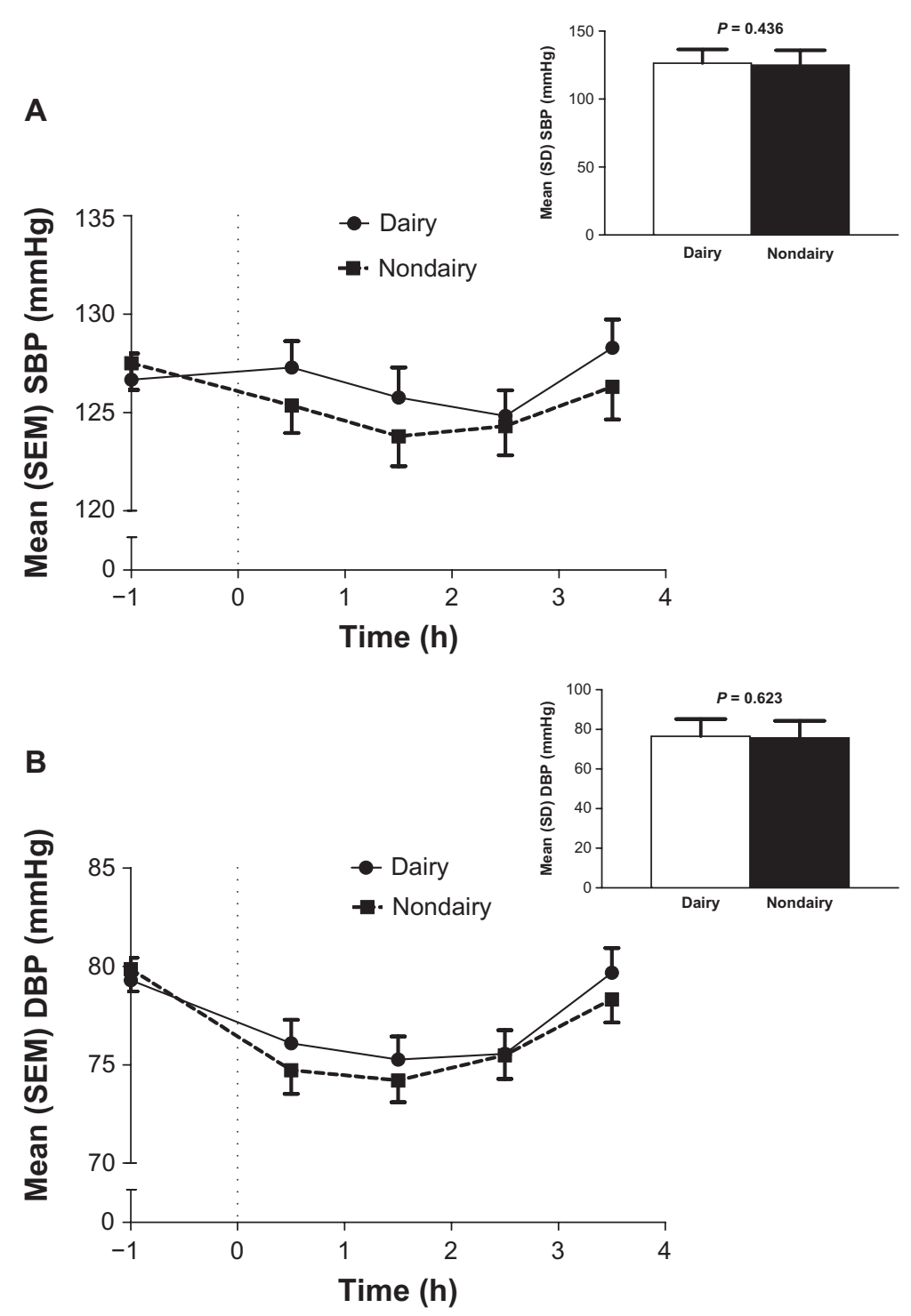

Figure I Mean systolic (A) and diastolic (B) blood pressure values at time points throughout a meal challenge test and overall mean (inset) for dairy and nondairy treatments $(\mathrm{N}=62)$. The average blood pressure was calculated as total $\mathrm{AUC}_{0-3.5 \mathrm{~h}}(\mathrm{~h} \times \mathrm{mmHg})$ or divided by $3.5 \mathrm{~h}$ (inset).

Abbreviations: AUC, area under the curve; DBP, diastolic blood pressure; h, hour(s); SBP, systolic blood pressure; SD, standard deviation; SEM, standard error of the mean.

premeal RHI value was significantly higher in the dairy condition compared to the nondairy condition $(2.32 \pm 0.19$ versus $1.50 \pm 0.04 ; P=0.002$ ). Mean SBP and DBP values from premeal to 3.5 hours postmeal (SBP, $124.1 \mathrm{mmHg}$ versus $121.3 \mathrm{mmHg}$; DBP, $75.5 \mathrm{mmHg}$ versus $73.1 \mathrm{mmHg}$ ) did not differ significantly between treatments in this subgroup, nor did fasting lipoprotein lipids (data not shown). Other subgroup analyses showed no significant differences between subjects with prehypertension and stage 1 hypertension, older and younger subjects, individuals with body mass index above or below the median, or between non-Hispanic white subjects and those of other race/ethnicity categories in any of the blood pressure or vascular function parameters measured (data not shown).
Fasting lipoprotein lipid (total-C, LDL-C, HDL-C, nonHDL-C, and TG) analyses of the overall sample indicated that dairy and nondairy treatments did not produce significantly different lipid responses (Table 4). Dietary energy, macronutrient, and mineral intakes at baseline and during each treatment condition are presented in Table 5. During the dairy treatment, subjects consumed significantly greater percentages of protein, total fat and saturated fatty acids, as well as greater amounts of calcium, magnesium, and potassium, and significantly less carbohydrate and dietary fiber compared to the nondairy treatment. Creatinine-adjusted concentrations of magnesium, calcium, chloride, potassium, and sodium in 24-hour urine samples were not significantly different between dairy and nondairy treatments in the overall 
Table 3 EndoPAT reactive hyperemia and augmentation indices of endothelial function for dairy and nondairy treatments before and after a meal challenge

\begin{tabular}{|c|c|c|c|}
\hline \multirow[t]{2}{*}{ Parameter } & \multicolumn{2}{|c|}{ Mean \pm SEM } & \multirow[t]{2}{*}{$P$-value } \\
\hline & Dairy & Nondairy & \\
\hline \multicolumn{4}{|c|}{ All subjects $(N=62)$} \\
\hline \multicolumn{4}{|c|}{ Reactive hyperemia index } \\
\hline Premeal $(-0.5$ h) & $2.35 \pm 0.08$ & $2.20 \pm 0.08$ & 0.229 \\
\hline Postmeal $(2.0 \mathrm{~h})$ & $2.33 \pm 0.08$ & $2.30 \pm 0.09$ & 0.646 \\
\hline \multicolumn{4}{|l|}{ Augmentation index } \\
\hline Premeal $(-0.5 \mathrm{~h})$ & $22.5 \pm 2.3$ & $23.8 \pm 2.7$ & 0.705 \\
\hline Postmeal $(2.0 \mathrm{~h})$ & $12.4 \pm 2.2$ & $13.2 \pm 2.4$ & 0.794 \\
\hline \multicolumn{4}{|c|}{ Subjects with endothelial dysfunction $(n=14)$} \\
\hline \multicolumn{4}{|c|}{ Reactive hyperemia index } \\
\hline Premeal $(-0.5$ h) & $2.32 \pm 0.19$ & $1.50 \pm 0.04$ & 0.002 \\
\hline Postmeal $(2.0 \mathrm{~h})$ & $2.34 \pm 0.19$ & $2.27 \pm 0.29$ & 0.383 \\
\hline \multicolumn{4}{|l|}{ Augmentation index } \\
\hline Premeal $(-0.5 \mathrm{~h})$ & $26.1 \pm 5.7$ & $23.6 \pm 5.5$ & 0.752 \\
\hline Postmeal $(2.0 \mathrm{~h})$ & $14.8 \pm 5.3$ & $12.5 \pm 3.9$ & 0.714 \\
\hline
\end{tabular}

Notes: ap-values were calculated from a repeated measures analysis of variance model between dairy and nondairy treatments.

Abbreviations: h, hour; SEM, standard error of the mean.

sample, or in the subgroup with endothelial dysfunction (data not shown).

Adverse events were experienced by $9(12.3 \%)$ subjects during the dairy treatment and 12 (16.4\%) subjects during the nondairy treatment $(P=0.140)$. None of the events were serious and all were classified as mild or moderate in severity. The most common adverse event was upper respiratory tract infection, reported by $4(5.5 \%)$ subjects in the dairy condition and $3(4.1 \%)$ subjects in the nondairy condition. One report of abdominal pain during the dairy condition was judged by the study physician to be probably related to consumption of study products, and five events during the nondairy condition

Table 4 Fasting lipids at baseline and percent changes from baseline to the end of each treatment period after dairy and nondairy conditions $(\mathrm{N}=62)$

\begin{tabular}{lcrll}
\hline Parameter & \multicolumn{2}{l}{ Mean \pm SEM } & P-value $^{\text {a }}$ \\
\cline { 2 - 4 } & \multicolumn{1}{l}{$\begin{array}{l}\text { Baseline, } \\
\text { mg/dL }\end{array}$} & \multicolumn{1}{l}{$\begin{array}{l}\text { Dairy, } \\
\end{array}$} & \multicolumn{1}{l}{$\begin{array}{l}\text { Nondairy, } \\
\end{array}$} & \\
\hline LDL-C & $132.1 \pm 3.8$ & $-2.9 \pm 1.3$ & $-3.3 \pm 1.1$ & 0.782 \\
Non-HDL-C & $159.6 \pm 4.5$ & $-2.3 \pm 1.1$ & $-2.2 \pm 1.0$ & 0.955 \\
Total-C & $210.2 \pm 4.4$ & $-2.0 \pm 0.8$ & $-2.4 \pm 0.9$ & 0.767 \\
HDL-C & $50.6 \pm 1.9$ & $-0.9 \pm 1.3$ & $-2.4 \pm 1.6$ & 0.459 \\
TG & $138.4 \pm 8.8$ & $3.3 \pm 3.7$ & $6.5 \pm 3.5$ & 0.368 \\
Total-C/HDL-C & $4.47 \pm 0.17$ & $-0.4 \pm 1.3$ & I.I \pm 1.5 & 0.668 \\
\hline
\end{tabular}

Notes: ap-values were calculated from a repeated measures analysis of variance model between dairy and nondairy treatments.

Abbreviations: HDL-C, high-density lipoprotein cholesterol; LDL-C, low-density lipoprotein cholesterol; Non-HDL-C, non-high-density lipoprotein cholesterol; TG, triglycerides; Total-C, total cholesterol; SEM, standard error of the mean. were considered to be possibly or probably related to treatment [dyspepsia $(\mathrm{n}=1)$, flatulence $(\mathrm{n}=1)$, hypertension $(\mathrm{n}=1)$, and weight increase $(\mathrm{n}=2)]$. All other events were described as unrelated or unlikely to be related to consumption of study products.

\section{Discussion}

This randomized, crossover trial failed to demonstrate a significant effect of 5 weeks consumption of low-fat dairy products versus low-fat nondairy products on SBP and DBP, vascular function, or plasma lipids in men and postmenopausal women with prehypertension or stage 1 hypertension. However, among the subgroup of subjects with endothelial dysfunction, defined as baseline RHI $\leq 1.67,{ }^{47,48}$ the RHI measured immediately prior to a meal challenge administered at the end of each treatment period was significantly higher in the dairy versus nondairy condition ( 2.32 versus $1.50, P=0.002)$. A higher degree of reactive hyperemia is consistent with the hypothesis that dairy foods might be of value for improving endothelial function in those with endothelial dysfunction. However, this result should be interpreted with caution because, similar to what was shown in the overall analysis, blood pressures did not differ between the two treatment conditions, nor did the 2-hour-postmeal RHI values.

Results from the DASH trial ${ }^{7}$ and several other crosssectional and prospective cohort studies support an inverse association between chronic consumption of dairy products (most often low-fat dairy products) and blood pressure. ${ }^{8-14,16,17,19,20} \mathrm{~A}$ recent meta-analysis reported a $13 \%$ reduction in the risk for the development of elevated blood pressure in adults consuming higher versus lower quantities of dairy. ${ }^{19}$ However, results in the literature regarding the relationship between dairy consumption and blood pressure are not entirely consistent, in part due to the wide variety of types of foods classified as dairy products (liquid and solid, low fat and whole fat, fermented and nonfermented) $)^{49}$ and likely also due to the age and health of the individuals examined. An intervention trial of 8 weeks consumption of low-fat dairy versus carbohydrate-rich control products by overweight and obese men and women produced a significant SBP-lowering effect $(-2.9 \mathrm{mmHg}$ compared with the control period, $P=0.027),{ }^{18}$ but some clinical studies conducted in healthy older adults and in young normotensive adults have failed to detect an effect of fluid milk or low-fat dairy products on blood pressure. ${ }^{50-52}$

To the authors' knowledge, this is the first clinical investigation of the effects of consumption of low-fat dairy 
Table 5 Intake of energy, macronutrients, and minerals at baseline and during dairy and nondairy treatment periods

\begin{tabular}{|c|c|c|c|c|}
\hline \multirow[t]{2}{*}{ Parameter } & \multicolumn{3}{|c|}{ Mean \pm SEM } & \multirow[t]{2}{*}{$P$-value ${ }^{\text {a }}$} \\
\hline & Baseline & Dairy & Nondairy & \\
\hline Energy (kcal/d) & $1748 \pm 67.2$ & $1740 \pm 51.6$ & $1750 \pm 58.5$ & 0.867 \\
\hline Carbohydrate (\% energy) & $47.7 \pm 1.2$ & $42.8 \pm 1.6$ & $48.0 \pm 1.7$ & 0.003 \\
\hline Protein (\% energy) & $17.1 \pm 0.8$ & $18.7 \pm 0.9$ & $15.0 \pm 0.8$ & $<0.001$ \\
\hline Total Fat (\% energy) & $33.4 \pm 1.1$ & $30.0 \pm 1.2$ & $26.4 \pm 1.1$ & 0.008 \\
\hline SFA (\% energy) & $10.5 \pm 0.5$ & $9.9 \pm 0.4$ & $8.1 \pm 0.4$ & 0.004 \\
\hline PUFA (\% energy) & $4.8 \pm 0.3$ & $4.0 \pm 0.2$ & $3.7 \pm 0.3$ & 0.226 \\
\hline MUFA (\% energy) & $8.9 \pm 0.5$ & $7.2 \pm 0.5$ & $6.9 \pm 0.4$ & 0.645 \\
\hline Dietary fiber (g/d) & $17.5 \pm 1.3$ & $15.3 \pm 0.9$ & $18.9 \pm 1.1$ & 0.003 \\
\hline Soluble fiber $(g / d)$ & $1.7 \pm 0.2$ & $1.7 \pm 0.1$ & $1.4 \pm 0.1$ & 0.118 \\
\hline Cholesterol (mg/d) & $244 \pm 14.0$ & $252 \pm 14.2$ & $228 \pm 12.2$ & 0.210 \\
\hline Calcium (mg/d) & $603 \pm 31.5$ & $1068 \pm 17.7$ & $46 I \pm 18.7$ & $<0.001$ \\
\hline Magnesium (mg/d) & $211 \pm 12.5$ & $238 \pm 10.3$ & $206 \pm 10.2$ & 0.006 \\
\hline Potassium (mg/d) & $1945 \pm 96.4$ & $2375 \pm 67.1$ & $1925 \pm 78.0$ & $<0.001$ \\
\hline Sodium (mg/d) & $2665 \pm 172$ & $2597 \pm 109$ & $2676 \pm 114$ & 0.667 \\
\hline
\end{tabular}

Notes: ${ }^{P}$-values were calculated from a repeated measures analysis of variance model between dairy and nondairy treatments.

Abbreviations: d, day; MUFA, monounsaturated fatty acids; PUFA, polyunsaturated fatty acids; SEM, standard error of the mean; SFA, saturated fatty acids.

products on RHI and AI. The effect of total dairy intake on arterial stiffness was recently examined by Crichton et $\mathrm{al}^{53}$ in a cross-sectional analysis of a subset of the Maine-Syracuse Longitudinal Study. A linear decrease in carotid-femoral pulse wave velocity was observed across increasing intakes of dairy food consumption (ranging from never/rarely to daily dairy food intake).

Subjects in the present trial consumed 1 serving per day each of low-fat milk, cheese, and yogurt, which is in accordance with the American Heart Association recommendations to consume 2-3 servings/day of low-fat dairy products, ${ }^{54}$ but the different nutrient compositions of these dairy foods may have heterogeneous effects on blood pressure. ${ }^{55}$ In their meta-analysis, Ralston et al ${ }^{19}$ examined specific categories of dairy foods and found that consumption of fluid dairy foods (including low-fat and full-fat milk and yogurt) was associated with an $8 \%$ reduction in the risk for elevated blood pressure (relative risk $0.92 ; 95 \%$ confidence interval, 0.87-0.98), whereas cheese consumption was not significantly associated with risk. ${ }^{19}$ In the present trial, the inclusion of cheese may have attenuated the effects of milk and yogurt on blood pressure and/or endothelial function. Milk and other fluid dairy foods have higher potassium and lower sodium content than cheese, which may partly explain the lack of association between blood pressure and cheese consumption. Sodium is considered to be a pivotal dietary factor in the development of hypertension, ${ }^{56}$ and in the DASH sodium study, ${ }^{57}$ among others, reducing sodium intake decreased blood pressure. Conversely, potassium intake has been shown to have an inverse relationship with the risk for developing hypertension. A meta-analysis of randomized trials that evaluated the effects of increased potassium intake on blood pressure concluded that potassium supplementation (average of at least $60 \mathrm{mmol}$ per day) lowered SBP and DBP by 4.4 and $2.5 \mathrm{mmHg}$, respectively, in hypertensive subjects, and by 1.8 and $1.0 \mathrm{mmHg}$ in normotensive subjects. ${ }^{58} \mathrm{In}$ the DASH trial, a diet rich in fruits and vegetables, compared with the typical American diet, reduced SBP and DBP at a constant level of sodium intake. ${ }^{7}$ The potassium content of the fruit and vegetable diet was more than twice that of the typical American diet, and this higher potassium:sodium ratio was speculated to account, at least in part, for the observed reduction in blood pressure. Several components in dairy foods are suspected of modulating the relationship between dairy consumption and blood pressure. ${ }^{59}$ The majority of research results point to the benefits of increased calcium for maintaining smooth muscle tone in blood vessels. ${ }^{60-62}$ In the Women's Health Study, consumption of dairy calcium, but not calcium supplementation, was associated with reduced risk of hypertension, ${ }^{13}$ suggesting that other dairy food components such as magnesium, ${ }^{63}$ potassium, ${ }^{56}$ and vitamin $\mathrm{D}^{64}$ could also play important roles.

Lactopeptides, bioactive peptides released during milk protein digestion (or during food processing), may also be involved in the relationship between dairy consumption and blood pressure. ${ }^{65-69}$ These inhibit the action of angiotensin I converting enzyme, thus reducing blood levels of angiotensin, preventing blood vessel constriction, and modulating endothelial function. Ballard et $\mathrm{a}^{68}$ demonstrated that 2 weeks' consumption of 5 grams per day of a novel whey-derived peptide (NOP-47) by healthy subjects significantly improved brachial artery flow-mediated dilation 
responses. Certain peptides derived from milk proteins may also modulate enothelin-1 release by endothelial cells. ${ }^{70}$ Endothelins are proteins that constrict blood vessels, thereby raising blood pressure. The importance of dietary phosphorous for lowering blood pressure was also recently suggested. ${ }^{71}$

In the present trial, total and saturated fat intakes were significantly higher in the dairy $(30.0 \%$ and $9.9 \%$ of energy, respectively) versus nondairy treatments $(26.9 \%$ and $8.1 \%$, respectively), but intakes during both conditions were lower than at baseline (33.4\% and $10.5 \%$, respectively), and there was no apparent effect of the consumption of dairy versus nondairy products on lipid levels. There is a widespread, though not fully substantiated, belief that consumption of milk, which can contain significant quantities of saturated fat, increases plasma cholesterol concentration and risk for vascular disease. ${ }^{6,55,72,73}$ In the present study, no adverse effects were noted for lipids, blood pressure, or vascular function during the dairy and nondairy food treatment periods, despite greater total and saturated fat intakes during dairy food consumption.

In the meta-analysis by Ralston et $\mathrm{al},{ }^{19} \mathrm{a}$ comparison of low-fat versus whole-fat dairy foods indicated a $16 \%$ reduction in the risk for elevated blood pressure associated with low-fat dairy foods and no association with whole-fat dairy foods, resulting in an overall reduction in risk associated with total dairy foods of $13 \%$. It has been proposed that when consumed with fat, the bivalent cations of calcium and magnesium in dairy products (both of which have been shown to be inversely associated with blood pressure and risk of developing hypertension) bind to fatty acids in the small intestine, forming insoluble soaps and partially preventing absorption of these minerals. ${ }^{10,74}$ The reduced mineral absorption might diminish the efficacy of whole-fat dairy products for lowering blood pressure. The processing of skim milk from whole milk introduces other changes in the nutritional composition besides simply removing the fat, and this could also contribute to the difference in blood pressure responses between low-fat and whole-fat dairy foods. ${ }^{13}$ Individuals who consume more low-fat dairy foods also tend to have a healthier lifestyle than those who consume full-fat dairy foods, which may confound observational analyses of dairy intake. Additional research is necessary to more fully understand the relationship between consumption of dairy products and blood lipids.

Prior research regarding the induction of acute postprandial endothelial dysfunction has focused on changes in endothelial function and oxidative stress that occur 2-3 hours after a single high-fat or high-carbohydrate meal. ${ }^{23-25,27,31}$ The amount of fat administered in the high-fat meals typically ranges between $\sim 35 \%$ and $50 \%$ of calories. ${ }^{25,26,28-30}$ In the present study, the standard meal provided $35 \%$ of calories as fat. Although the meal challenge appeared to induce endothelial dysfunction based on a nearly $50 \%$ decrease in the AI from premeal to postmeal, the RHI in both treatment conditions changed very little from premeal to postmeal. This brings into question whether the meal challenge was a sufficient "endothelial insult" from which to detect an acute effect of the dairy versus nondairy products, and whether 2 hours postmeal was the most appropriate postprandial time point for assessment.

A limitation of the present investigation is that the subjects studied had, as a group, mild blood pressure elevation and a low prevalence of endothelial dysfunction. Subjects were selected based on their blood pressure status of prehypertension $(84 \%)$ or stage 1 hypertension $(16 \%)$, but according to their baseline RHI scores (overall mean $\sim 2.3$ ) the subjects had relatively healthy endothelial responses. The results for the 14 subjects with endothelial dysfunction $(\mathrm{RHI} \leq 1.67)$ suggest that a significant association between dairy intake and blood pressure and vascular measures might have been detectable in a larger sample selected specifically for the presence of endothelial dysfunction.

\section{Conclusion}

In conclusion, these results showed that among men and women with prehypertension or stage 1 hypertension, there were no significant effects of consuming low-fat dairy products, compared with nondairy products, on blood pressure, measures of vascular function, or lipid variables. However, in a subgroup of subjects with baseline endothelial dysfunction, the premeal RHI was significantly higher in the dairy versus nondairy condition. Further research is warranted to investigate the possibility that the consumption of dairy products might be of value for improving endothelial function in subjects selected for the presence of endothelial dysfunction at baseline.

\section{Acknowledgments}

This study was funded by Dairy Research Institute, Rosemont, IL. The authors also wish to thank Valerie Kaden and Kristen Sanoshy, MPH, RHIA, both with Biofortis Clinical Research, for their assistance with project oversight and data collection.

\section{Disclosure}

The authors report no conflicts of interest in this work. KC Maki, TM Rains, AL Schild, MR Dicklin, AL Lawless, and KM Kelley as employees of Biofortis Clinical Research received a research grant from Dairy Research Institute to conduct this research. 
KM Park was an employee of Dairy Research Institute/National Dairy Council at the time the study was initiated.

\section{References}

1. Kearney PM, Whelton M, Reynolds K, Muntner P, Whelton PK, He J. Global burden of hypertension: analysis of worldwide data. Lancet. 2005;365(9455):217-223.

2. Health, United States, 2011: With Special Feature on Socioeconomic Status and Health. Hyattsville (MD): National Center for Health Statistics (US); May 2012. Available from: http://www.cdc.gov/nchs/data/ hus/hus11.pdf Accessed June 11, 2013.

3. US Department of Health and Human Services. National Institutes of Health National Heart, Lung, and Blood Institute. National High Blood Pressure Education Program. The Seventh Report of the Joint National Committee on Prevention, Detection, Evaluation and Treatment of High Blood Pressure. NIH Publication No 04-5230. August 2004.

4. Chobanian AV, Bakris GL, Black HR, et al. The Seventh Report of the Joint National Committee on Prevention, Detection, Evaluation, and Treatment of High Blood Pressure: the JNC 7 report. JAMA. 2003;289(19):2560-2572.

5. Hsia J, Margolis KL, Eaton CB, et al; for the Women's Health Initiative Investigators. Prehypertension and cardiovascular disease risk in the Women's Health Initiative. Circulation. 2007;115(7):855-860.

6. Appel LJ, Brands MW, Daniels SR, et al. Dietary approaches to prevent and treat hypertension: a scientific statement from the American Heart Association. Hypertension. 2006;47(2):296-308.

7. Appel LJ, Moore TJ, Obarzanek E, et al. A clinical trial of the effects of dietary patterns on blood pressure. DASH Collaborative Research Group. N Engl J Med. 1997;336(16):1117-1124.

8. Miller GD, DiRienzo DD, Reusser ME, McCarron DA. Benefits of dairy product consumption on blood pressure in humans: a summary of the biomedical literature. J Am Coll Nutr. 2000;19(Suppl 2):147S-164S.

9. Pereira MA, Jacobs DR Jr, Van Horn L, Slattery ML, Kartashov AI, Ludwig DS. Dairy consumption, obesity, and the insulin resistance syndrome in young adults: the CARDIA Study. JAMA. 2002;287(16): 2081-2089.

10. Alonso A, Beunza JJ, Delgado-Rodríquez M, Martínez JA, MartínezGonzález MA. Low-fat dairy consumption and reduced risk of hypertension: the Seguimiento Universidad de Navarra (SUN) cohort. Am J Clin Nutr. 2005;82(5):972-979.

11. Ruidavets JB, Bongard V, Simon C, et al. Independent contribution of dairy products and calcium intake to blood pressure variations at a population level. J Hypertens. 2006;24(4):671-681.

12. Snijder MB, van der Heijden AA, van Dam RM, et al. Is higher dairy consumption associated with lower body weight and fewer metabolic disturbances? The Hoorn Study. Am J Clin Nutr. 2007;85(4):989-995.

13. Wang L, Manson JE, Buring JE, Lee IM, Sesso HD. Dietary intake of dairy products, calcium, and vitamin D and the risk of hypertension in middle-aged and older women. Hypertension. 2008;51(4): 1073-1079.

14. Engberink MF, Hendriksen MA, Schouten EG, et al. Inverse association between dairy intake and hypertension: the Rotterdam Study. Am J Clin Nutr. 2009;89(6):1877-1883.

15. Hilpert KF, West SG, Bagshaw DM, et al. Effects of dairy products on intracellular calcium and blood pressure in adults with essential hypertension. J Am Coll Cardiol. 2009;28(2):142-149.

16. Kris-Etherton PM, Grieger JA, Hilpert KF, West SG. Milk products, dietary patterns and blood pressure management. J Am Coll Nutr. 2009;28(Suppl 1):103S-119S.

17. Toledo E, Delgado-Rodríguez M, Estruch R, et al. Low-fat dairy products and blood pressure: follow-up of 2290 older persons at high cardiovascular risk participating in the PREDIMED study. Br J Nutr. 2009;101(1):59-67.

18. van Meijl L, Mensink R. Low-fat dairy consumption reduces systolic blood pressure, but does not improve other metabolic risk parameters in overweight and obese subjects. Nutr Metab Cardiovasc Dis. 2011; 21(5):355-361.

19. Ralston RA, Lee JH, Truby H, Palermo CE, Walker KZ. A systematic review and meta-analysis of elevated blood pressure and consumption of dairy foods. J Hum Hypertens. 2012;26(1):3-13.

20. Soedamah-Muthu SS, Verberne LD, Ding EL, Engberink MF, Geleijnse JM. Dairy consumption and incidence of hypertension: a doseresponse meta-analysis of prospective cohort studies. Hypertension. 2012;60(5):1131-1137.

21. Dharmashankar K, Widlansky ME. Vascular endothelial function and hypertension: insights and directions. Curr Hypertens Rep. 2010;12(6):448-455.

22. Rubinshtein R, Kuvin JT, Soffler M, et al. Assessment of endothelial function by non-invasive peripheral arterial tonometry predicts late cardiovascular adverse events. Eur Heart J. 2010;31(9):1142-1148.

23. Vogel RA, Corretti MC, Plotnick GD. Effect of a single high-fat meal on endothelial function in healthy subjects. Am J Cardiol. 1997;79(3): $350-354$.

24. Plotnick GD, Corretti MC, Vogel RA. Effect of antioxidant vitamins on the transient impairment of endothelium-dependent brachial artery vasoactivity following a single high-fat meal. JAMA. 1997; 278(20):1682-1686.

25. Plotnick GD, Corretti MC, Vogel RA, Hesslink R Jr, Wise JA. Effect of supplemental phytonutrients on impairment of the flow-mediated brachial artery vasoactivity after a single high-fat meal. J Am Coll Cardiol. 2003;41(10):1744-1749.

26. Cuevas AM, Guasch V, Castillo O, et al. A high-fat diet induces and red wine counteracts endothelial dysfunction in human volunteers. Lipids. 2000;35(2):143-148.

27. Nappo F, Esposito K, Cioffi M, et al. Postprandial endothelial activation in healthy subjects and in type 2 diabetic patients: role of fat and carbohydrate meals. J Am Coll Cardiol. 2002;39(7):1145-1150.

28. Tushuizen ME, Nieuwland R, Scheffer PG, Sturk A, Heine RJ, Diamant M. Two consecutive high-fat meals affect endothelialdependent vasodilation, oxidative stress and cellular microparticles in healthy men. J Thromb Haemost. 2006;4(5):1003-1010.

29. Berry SE, Tucker S, Banerji R, et al. Impaired postprandial endothelial function depends on the type of fat consumed by healthy men. J Nutr. 2008;138(10):1910-1914.

30. Ayer JG, Harmer JA, Steinbeck K, Celermajer DS. Postprandial vascular reactivity in obese and normal weight young adults. Obesity (Silver Spring). 2010;18(5):945-951.

31. Barriger TA, Hatcher L, Sasser HC. Potential benefits on impairment of endothelial function after a high-fat meal of 4 weeks of flavonoid supplementation. Evid Based Complement Alternat Med. 2011;2011:796958.

32. Katz DL, Nawaz H, Boukhalil J, et al. Acute effects of oats and vitamin E on endothelial responses to ingested fat. Am J Prev Med. 2001;20(2):124-129.

33. Ling L, Zhao SP, Gao M, Zhou QC, Li YL, Xia B. Vitamin C preserves endothelial function in patients with coronary heart disease after a high-fat meal. Clin Cardiol. 2002;25(5):219-224.

34. Cortés B, Nuñez I, Cofán M, et al. Acute effects of high-fat meals enriched with walnuts or olive oil on postprandial endothelial function. J Am Coll Cardiol. 2006;48(8):1666-1671.

35. Chaves AA, Joshi MS, Coyle CM, et al. Vasoprotective endothelial effects of a standardized grape product in humans. Vascul Pharmacol. 2009;50(1-2):20-26.

36. Kato T, Inoue T, Node K. Postprandial endothelial dysfunction in subjects with new-onset type 2 diabetes: an acarbose and nateglinide comparative study. Cardiovasc Diabetol. 2010;9:12.

37. Vehkavaara S, Mäkimattila S, Schlenzka A, Vakkilainen J, Westerbacka J, Yki-Järvinen H. Insulin therapy improves endothelial function in type 2 diabetes. Arterioscler Thromb Vasc Biol. 2000;20(2):545-550.

38. Guven GS, Atalar E, Yavuz B, et al. Simvastatin treatment improves endothelial function and increases fibrinolysis in patients with hypercholesterolemia. J Natl Med Assoc. 2006;98(4):627-630. 
39. Hosokawa S, Hiasa Y, Miyazaki S, et al. Effects of smoking cessation on coronary endothelial function in patients with recent myocardial infarction. Int J Cardiol. 2008;128(1):48-52.

40. Tyldum GA, Schjerve IE, Tjønna AE, et al. Endothelial dysfunction induced by post-prandial lipemia: complete protection afforded by high-intensity aerobic interval exercise. J Am Coll Cardiol. 2009;53(2):200-206.

41. Bigornia SJ, Mott MM, Hess DT, et al. Long-term successful weight loss improves vascular endothelial function in severely obese individuals. Obesity (Silver Spring). 2010;18(4):754-759.

42. National Cholesterol Education Program (NCEP) Expert Panel on Detection, Evaluation, and Treatment of High Blood Cholesterol in Adults (Adult Treatment Panel III). Third Report of the National Cholesterol Education Program (NCEP) Expert Panel on Detection, Evaluation, and Treatment of High Blood Cholesterol in Adults (Adult Treatment Panel III) final report. Circulation. 2002;106(25):3143-3421.

43. Kuvin JT, Patel AR, Sliney KA, et al. Assessment of peripheral vascular endothelial function with finger arterial pulse wave amplitude. $\mathrm{Am}$ Heart J. 2003;146(1):168-174.

44. Friedewald WT, Levy RI, Fredrickson DS. Estimation of the concentration of low-density lipoprotein cholesterol in plasma, without use of the preparative ultracentrifuge. Clin Chem. 1972;18(6):499-502.

45. Shapiro SS, Wilk MB. An analysis of variance test for normality (complete samples). Biometrika. 1965;52(3-4):591-611.

46. McNemar Q. Note on the sampling error of the difference between correlated proportions or percentages. Psychometrika. 1947;12:153-157.

47. Bonetti PO, Pumper GM, Higano ST, Holmes DR Jr, Kuvin JT, Lerman A. Noninvasive identification of patients with early coronary atherosclerosis by assessment of digital reactive hyperemia. J Am Coll Cardiol. 2004;44(11):2137-2141.

48. Itamar-Medical.com [webpage on the Internet]. Available from: http:// www.itamar-medical.com/EndoPAT/FAQ.html. Accessed March 19, 2013.

49. McGrane MM, Essery E, Obbagy J, et al. Dairy consumption, blood pressure, and risk of hypertension: an evidence-based review of recent literature. Curr Cardiovasc Risk Rep. 2011;5(4):287-298.

50. Barr SI, McCarron DA, Heaney RP, et al. Effects of increased consumption of fluid milk on energy and nutrient intake, body weight, and cardiovascular risk factors in healthy older adults. J Am Diet Assoc. 2000;100(7):810-817.

51. Steffen LM, Kroenke CH, Yu X, et al. Associations of plant food, dairy product, and meat intakes with 15-y incidence of elevated blood pressure in young black and white adults: the Coronary Artery Risk Development in Young Adults (CARDIA) Study. Am J Clin Nutr. 2005;82(6):1169-1177.

52. Alonso A, Zozaya C, Vázquez Z, Alfredo Martínez J, MartínezGonzález MA. The effect of low-fat versus whole-fat dairy product intake on blood pressure and weight in young normotensive adults. J Hum Nutr Diet. 2009;22(4):336-342.

53. Crichton GE, Elias MF, Dore GA, Abhayaratna WP, Robbins MA. Relations between dairy food intake and arterial stiffness: pulse wave velocity and pulse pressure. Hypertension. 2012;59(5):1044-1051.

54. Heart.org [webage on the Internet]. Available at: http://www.heart org/HEARTORG/GettingHealthy/NutritionCenter/HealthyDietGoals/ Suggested-Servings-from-Each-Food-Group_UCM_318186_Article. jsp. Accessed March 19, 2013.
55. Gibson RA, Makrides M, Smithers LG, Voevodin M, Sinclair AJ. The effect of dairy foods on CHD: a systematic review of prospective cohort studies. Br J Nutr. 2009;102(9):1267-1275.

56. Androgué HJ, Madias NE. Sodium and potassium in the pathogenesis of hypertension. N Engl J Med. 2007;356(19):1966-1978.

57. Sacks FM, Svetkey LP, Vollmer WM, et al. Effects on blood pressure of reduced dietary sodium and the Dietary Approaches to Stop Hypertension (DASH) diet. N Engl J Med. 2001;344:3-10.

58. Whelton PK, He J, Cutler JA, et al. Effects of oral potassium on blood pressure: meta-analysis of randomized controlled clinical trials. JAMA. 1997;277:1624-1632.

59. Rice BH, Cifelli CJ, Pilosky MA, Miller GD. Dairy components and risk factors for cardiometabolic syndrome: recent evidence and opportunities for future research. Adv Nutr. 2011;2(5):396-407.

60. Allender PS, Cutler JA, Follmann D, Cappuccio FP, Pryer J, Elliott P. Dietary calcium and blood pressure: a meta-analysis of randomized clinical trials. Ann Intern Med. 1996;124(9):825-831.

61. Bucher HC, Cook RJ, Guyatt GH, et al. Effects of dietary calcium supplementation on blood pressure: a meta-analysis of randomized controlled trials. JAMA. 1996;275(13):1016-1022.

62. Griffith LE, Guyatt GH, Cook RJ, Bucher HC, Cook DJ. The influence of dietary and non-dietary calcium supplementation on blood pressure: an updated meta-analysis of randomized controlled trials. Am J Hypertens. 1999;12(1 Pt 1):84-92.

63. Jee SH, Miller ER 3rd, Guallar E, Singh VK, Appel LJ, Klag MJ. The effect of magnesium supplementation on blood pressure: a meta-analysis of randomized clinical trials. Am J Hypertens. 2002;15(8):691-696.

64. Nemerovski CW, Dorsch MP, Simpson RU, Bone HG, Aaronson KD, Bleske BE. Vitamin D and cardiovascular disease. Pharmacotherapy. 2009;29(6):691-708.

65. Clare DA, Swaisgood HE. Bioactive milk peptides: a prospectus. J Dairy Sci. 2000;83(6):1187-1195.

66. FitzGerald RJ, Murray BA, Walsh DJ. Hypotensive peptides from milk proteins. J Nutr. 2004;134(4);980S-988S.

67. Séverin S, Wenshui X. Milk biologically active components as nutraceuticals: review. Crit Rev Food Sci Nutr. 2005;45(7-8):645-656.

68. Ballard KD, Bruno RS, Seip RL, et al. Acute ingestion of a novel wheyderived peptide improves vascular endothelial responses in healthy individuals: a randomized, placebo controlled trial. Nutr J. 2009;8:34.

69. Boelsma E, Kloek J. Lactotripeptides and antihypertensive effects: a critical review. Br J Nutr. 2009;101(6):776-786.

70. Maes W, Van Camp J, Vermeirssen V, et al. Influence of the lactokinin Ala-Leu-Pro-Met-His-Ile-Arg (ALPMHIR) on the release of endothelin-1 by endothelial cells. Regul Pept. 2004;118(1-2):105-109.

71. Alonso A, Nettleton JA, Ix JH, et al. Dietary phosphorous, blood pressure, and incidence of hypertension in the Atherosclerosis Risk In Communities study and the Multi-Ethnic Study of Atherosclerosis. Hypertension. 2010;55(3):776-784.

72. German JB, Gibson RA, Krauss RM, et al. A reappraisal of the impact of dairy foods and milk fat on cardiovascular disease risk. Eur J Nutr. 2009;48(4):191-203.

73. Elwood PC, Pickering JE, Givens DI, Gallacher JE. The consumption of milk and dairy foods and the incidence of vascular disease and diabetes: an overview of the evidence. Lipids. 2010;45:925-939.

74. Vaskonen T. Dietary minerals and modifications of cardiovascular risk factors. J Nutr Biochem. 2003;14(9):492-506.
Vascular Health and Risk Management

\section{Publish your work in this journal}

Vascular Health and Risk Management is an international, peerreviewed journal of therapeutics and risk management, focusing on concise rapid reporting of clinical studies on the processes involved in the maintenance of vascular health; the monitoring, prevention and treatment of vascular disease and its sequelae; and the involvement of

\section{Dovepress}

metabolic disorders, particularly diabetes. This journal is indexed on PubMed Central and MedLine. The manuscript management system is completely online and includes a very quick and fair peer-review system, which is all easy to use. Visit http://www.dovepress.com/ testimonials.php to read real quotes from published authors. 